\title{
ARTIGOS
}

Recebido em 31.08.2012. Aprovado em 17.06.2013

Avaliado pelo sistema double blind review. Editor Científico: César Alexandre de Souza

DOI: http://dx.doi.org/10.1590/So034-759020140205

\section{CONHECIMENTO COMPARTILHADO, RECURSOS DE TI E DESEMPENHO DE PROCESSOS DE NEGÓCIOS}

\author{
Shared knowledge, IT resources and business process performance \\ Conocimiento compartido, recursos de TI y rendimiento de procesos de negocios
}

\begin{abstract}
RESUMO
Esta pesquisa investiga os efeitos de recursos e capacidades associados à Tecnologia da Informação (TI), e do conhecimento compartilhado entre gestores das áreas de TI e de negócios, no alinhamento operacional entre essas áreas e, por conseguinte, no desempenho de processos de negócios. 0 estudo baseia-se em dados coletados nas áreas de TI e de retaguarda (back office) de 39 empresas prestadoras de serviços do Rio de Janeiro. Resultados observados por meio da análise de equações estruturais sugerem que o alinhamento operacional afeta positivamente o desempenho de processos de back office, e este, a satisfação de seus clientes. Embora recursos e capacidades de TI, assim como o compartilhamento de conhecimento, não tenham efeito direto sobre o nível de alinhamento operacional, quanto maior o compartilhamento de conhecimento entre as áreas de TI e de negócio, mais intensa e positiva a associação entre a flexibilidade da infraestrutura de TI e o alinhamento operacional entre as áreas. 0 artigo discute as implicações teóricas e práticas dessas observações.
\end{abstract}

PALAVRAS-CHAVE | Conhecimento compartilhado, alinhamento operacional entre TI e negócio, recursos e capacidades de TI, visão baseada em recursos (VBR), processos de negócios.

VALTER DE ASSIS MORENO JUNIOR valter.moreno@gmail.com Professor do Departamento de Administração, Faculdades Ibmec, Rio de Janeiro, RJ - Brasil

\section{FLÁVIA DE SOUZA COSTA NEVES CAVAZOTTE}

flavia.cavazotte@iag.puc-rio.br Professora da Escola de Negócios, Pontifícia Universidade Católica do Rio de Janeiro, Rio de Janeiro, RJ Brasil

\section{RICARDO REIS ARRUDA}

rrarruda@globo.com Mestre em Administração pela Faculdade de Economia e Finanças, Faculdades Ibmec, Rio de Janeiro, RJ - Brasil

\begin{abstract}
This research assesses the effects of resources and capabilities related to Information Technology (IT), and of shared knowledge among IT and business managers, on the level of operational alignment between these areas, and, thereby, on the performance of business processes. Data was collected from IT and back office managers of 39 companies from Rio de Janeiro that operate in the service sector. Results of structural equations analysis suggest that operational alignment positively affects the performance of back office processes, which, by its turn, influences the satisfaction of process customers. Although IT resources and capabilities, as well as shared knowledge, do not seem to have a direct effect on the level of operational alignment, it was observed that, as IT and business areas share more knowledge, the flexibility of a company's IT infrastructure tends to have stronger, positive effects on operational alignment. The results are discussed with their implications for theory and practice.

KEYWORDS / Shared knowledge, business-IT operational alignment, IT resources and capabilities, resource based view (RBV), business process.
\end{abstract}

\section{RESUMEN}

Esta investigación trata sobre los efectos de recursos y capacidades asociados a la Tecnología de la Información (TI), y del conocimiento compartido entre gestores de las áreas de TI y de negocios, en la alineación operacional entre esas áreas y, por consiguiente, en el desempeño de procesos de negocios. El estudio se basa en datos recolectados en las áreas de TI y de retaguardia (back office) de 39 empresas prestadoras de servicios de Rio de Janeiro. Los resultados observados por medio del análisis de ecuaciones estructurales sugieren que la alineación operacional afecta positivamente el desempeño de procesos de back office, y este, la satisfacción de sus clientes. Aunque recursos y capacidades de $\mathrm{Tl}$, así como el compartir conocimiento, no tengan efecto directo sobre el nivel de alineación operacional, cuanto mayor el intercambio de conocimiento entre las áreas de TI y de negocio, más intensa y positiva la asociación entre la flexibilidad de la infraestructura de TI y la alineación operacional entre las áreas. El artículo discute las implicancias teóricas y prácticas de esas observaciones.

PALABRAS-CLAVE / Conocimiento compartido, alineación operacional entre TI y negocio, recursos y capacidades de TI, visión basada en recursos (VBR), procesos de negocios. 


\section{INTRODUÇÃO}

Em função da queda de barreiras comerciais e dos preços de recursos de TI, hoje em dia, empresas concorrentes podem ter igual acesso a hardware, software e equipamentos de TI disponíveis no mercado. Diversos pesquisadores, assim, apoiados na teoria da visão baseada em recursos (resource-based view - RBV) (Wernerfelt, 1984; Barney, 1991; cf. Melville, Kraemer \& Gurbaxani, 2004; Wade \& Hulland, 2004; Kretzer \& Menezes, 2006), argumentam que investimentos em ativos de TI não são capazes, por si só, de gerar vantagem competitiva sustentável. Na opinião desses autores, é a forma como os recursos de TI são efetivamente utilizados pelas empresas que determina sua capacidade de agregar valor para o negócio (Nevo \& Wade, 2010; Przyczynski \& Vanti, 2012). Em linha com essas ideias, vários pesquisadores (exs.: Bassellier, Bensabat \& Reich, 2003; Bassellier \& Bensabat, 2004; Bhatt \& Grover, 2005; Jeffers, Muhanna \& Nault, 2008; Kim, Shin, Kim \& Lee, 2011) avaliaram habilidades de gerenciamento de TI como fonte de vantagem competitiva, sugerindo que elas são um recurso único criado no contexto histórico-social próprio da empresa e que, por conseguinte, não pode ser diretamente transferido para outras organizações (Wade \& Hulland, 2004; Nevo \& Wade, 2010).

Ao longo das últimas duas décadas, construtos associados à complementaridade e interação entre recursos (humanos ou tecnológicos) de TI e organizacionais, tais como alinhamento TI-negócio, e conhecimento e visão compartilhada entre TI e negócio, também vêm sendo investigados na literatura, especialmente no que tange a seus efeitos no desempenho de uma empresa (exs.: Moreno Jr., Cavazotte \& Valente, 2009; Preston \& Karahanna, 2009; Wong, Ngan, Chan \& Chong, 2012). Parece haver, no entanto, uma sobreposição nos domínios desses construtos, assim como limitações metodológicas em estudos empíricos realizados para avaliar seus antecedentes e efeitos (cf. Ray, Muhanna \& Barney, 2005; Przyczynski \& Vanti, 2012). Além disso, grande parte das pesquisas até então realizadas concentrou-se na influência direta dos referidos construtos no desempenho organizacional, deixando de lado potenciais mediadores ou determinantes dos resultados de um negócio.

Diversos autores enfatizam, também, que a investigação da capacidade de geração de valor da TI para uma firma deve ter por foco o impacto que essas tecnologias têm, em conjunto com recursos humanos de $\mathrm{Tl}$ e organizacionais complementares, nos processos de negócios da organização (Melville et al, 2004; Ray, Barney \& Muhanna, 2004; Bhatt \& Grover, 2005; Ray et al, 2005; Kim et al, 2011; Moreno Jr., Pinheiro \& Joia, 2012). A presente pesquisa avalia, assim, quantitativamente: (1) a influência conjunta de recursos e habilidades técnicas de TI de uma empresa, da flexibilidade de sua infraestrutura de TI, do seu nível de investimento nesse tipo de tecnologia e do compartilhamento de conhecimentos entre gestores das áreas de TI e de negócios no alinhamento operacional entre estas áreas, (2) a influência do grau de alinhamento operacional entre TI e negócio no desempenho de processos organizacionais, conforme percebido pelos gestores desses processos, e (3) a influência do desempenho dos referidos processos na satisfação de seus clientes.

Como, na maioria das empresas, as áreas de retaguarda (back office) são fortemente dependentes de ferramentas de TI (King, 2003), elas constituem um terreno fértil para a investigação dos tópicos discutidos acima. As áreas de retaguarda executam a maioria das atividades e tarefas de uma empresa, fornecendo apoio às áreas de frente (front office), que têm contato direto com os clientes. Apesar de não ser fonte direta de receita, o back office pode rapidamente dissipar os lucros gerados pelo front office, caso seus processos não alcancem níveis de eficiência e eficácia adequados. Este trabalho, assim, investiga empiricamente as relações anteriormente mencionadas com base em dados coletados nas áreas de TI e de back office de empresas prestadoras de serviços que atuam no Rio de Janeiro.

Na próxima seção, apresenta-se brevemente 0 arcabouço teórico que dá suporte à pesquisa realizada. Em seguida, são desenvolvidas as hipóteses que constituem o modelo proposto e detalhados os procedimentos metodológicos utilizados para testá-lo. Na sequência, apresentam-se os resultados obtidos com os dados coletados, concluindo com uma discussão de suas implicações acadêmicas e gerenciais, limitações do estudo e sugestões para pesquisas futuras.

\section{REFERENCIAL TEÓRICO}

Vários construtos associados ao compartilhamento e domínio de conhecimentos e habilidades por parte de profissionais de $\mathrm{Tl}$ e de negócios foram propostos na literatura, como o conhecimento gerencial de TI (Boynton, Zmud \& Jacobs, 1994; Wong et al, 2012) e o conhecimento compartilhado (Nelson \& Cooprider, 1996; Ray et al, 2005). O conceito de conhecimento compartiIhado contempla o conhecimento que os gestores de TI têm sobre os processos de negócios, o conhecimento que os gestores de negócio têm sobre as oportunidades potenciais no uso da TI para aprimorar os processos de suas áreas e o entendimento comum entre esses gestores sobre como a TI pode ser utilizada para melhorar o desempenho dos processos de negócios, respeitando as suas contribuições e desafios particulares (Boynton et al, 1994; Reich \& Benbasat, 2000; Bassellier et al, 2003; Bassellier \& Bensabat, 2004; Ray et al, 2005). Como tal, o co- 
nhecimento compartilhado possibilita o desenvolvimento, implantação e efetiva utilização de recursos de TI numa organização e maior eficácia de seus processos (Lee, Trauth \& Farwell, 1995; Nelson \& Cooprider, 1996; Pee, Kankanhalli \& Kim, 2010; Ranganathan \& Sethi, 2002). Revisões da literatura sobre o alinhamento entre TI e negócio sugerem que o nível de compartilhamento de conhecimento entre os gestores das áreas de negócio e de TI influencia positivamente o uso estratégico da TI nas empresas e o desempenho acima da média nos seus setores (Moreno Jr. et al, 2009; Preston \& Karahanna, 2009; cf. Armstrong \& Sambamurthy, 1999).

Num dos estudos mais completos sobre o tema, Ray et al. (2005) enfatizam a importância do conhecimento compartilhado entre os gerentes de TI e os gerentes de negócios para promover melhorias de desempenho por meio do uso ótimo da TI para apoiar os processos de negócios existentes (cf. Boynton et al, 1994; Ranganathan \& Sethi, 2002). Em seu artigo, os autores propõem e testam empiricamente um modelo envolvendo recursos e capacidades associados ao planejamento, concepção, implantação e uso de sistemas informatizados. 0 modelo assume que o conhecimento compartilhado modera os efeitos dos recursos e capacidades de $\mathrm{TI}$ no desempenho de um processo de negócio, além de influenciar diretamente esse desempenho. Os resultados das análises de regressão realizadas por Ray et al. (2005) validaram o efeito direto do conhecimento compartiIhado no desempenho de processos. Somente a hipótese relativa ao papel moderador do compartilhamento de conhecimento na relação entre a disponibilidade de recursos tecnológicos e o desempenho do processo, no entanto, obteve suporte. Desse modo, embora haja na literatura um consenso razoável quanto às ideias acima apresentadas, o suporte empírico que tais proposições obtiveram ainda é limitado. Vale, ainda, ressaltar que Ray et al. (2005) não incluíram em seu modelo o construto alinhamento entre TI e negócio, que vem sendo apontado como um importante mediador do efeito dos recursos de TI no desempenho organizacional (Kearns \& Sabherwal, 2006; Moreno Jr. et al, 2009; Preston \& Karahanna, 2009; Tian, Wang, Chen \& Johansson, 2010).

\section{Alinhamento operacional, desempenho do processo e desempenho organizacional}

Em sua revisão da literatura sobre alinhamento entre TI e negócio, Moreno Jr. et al. (2009, p. 38) definem alinhamento operacional como o grau de compatibilidade e sinergia entre a infraestrutura, processos e políticas das áreas de negócios e de $\mathrm{TI}$, conforme percebido pelos agentes organizacionais responsáveis pelas operações dessas áreas. Os autores indicam, ain- da, que resultados empíricos obtidos ao longo das últimas décadas suportam a ideia de que a obtenção e manutenção do alinhamento operacional, quando este é baseado em estratégias apropriadas e alinhadas para as áreas de TI e de negócios, tendem a gerar diversos benefícios para uma organização, inclusive vantagem competitiva. Tais resultados estão em consonância com a proposta de Melville et al. (2004) de um modelo integrado para o processo de geração de valor de negócio por meio da TI. Tendo por base uma ampla revisão da literatura, esses autores sugerem que os efeitos dos recursos de TI no desempenho organizacional são mediados por seu efeito no desempenho dos processos de negócios que tais recursos suportam. Mudanças no desempenho dos processos decorreriam, então, de alterações nos seus fluxos de trabalho e de informações, introduzidas com a adoção e uso de recursos de TI. Na medida em que tais alterações refletissem as reais necessidades da operação do processo, haveria um efeito positivo no seu desempenho e, por conseguinte, no resultado do negócio. Pode-se dizer, portanto, que, segundo Melville et al. (2004), o grau de alinhamento operacional entre TI e negócio media o efeito dos recursos de TI de uma empresa no desempenho dos seus processos de negócios, que, por sua vez, influenciam o desempenho organizacional (cf. Henderson \& Venkatraman, 2004).

Diversas evidências da importância do alinhamento entre os objetivos de um negócio, seus processos essenciais e o suporte prestado pelos recursos de TI podem ser encontradas na literatura nacional e internacional mais recente (exs.: Kim et al, 2011; Moreno Jr. et al, 2012; Przyczynski \& Vanti, 2012). Asato, Spinola, Costa e Silva (2011), por exemplo, descrevem como o alinhamento do processo de produção de software de uma empresa brasileira às estratégias por ela definidas resultaram no aumento da receita da organização. Tonolli, Brodbeck e Costa (2012, p. 165) também observaram que o alinhamento TI-negócio foi essencial para o atendimento das necessidades dos clientes e a conquista de novos mercados, assegurando a continuidade dos negócios. Vale, ainda, destacar o estudo de Kim et al. (2011), cujos resultados indicam que recursos e capacidades de TI (expertise técnica, capacidade de gestão de TI e flexibilidade da infraestrutura de $\mathrm{TI}$ ) são antecedentes importantes do desenvolvimento de capacidades dinâmicas orientadas a processos e do desempenho financeiro das empresas. Esses tópicos, de especial importância para o presente estudo, são tratados nas próximas seções.

\section{Expertise técnica e recursos de TI}

Expertise ou habilidades técnicas em TI são termos usualmente empregados para se referir à competência técnica que a equi- 
pe de TI de uma empresa possui, seja ela interna ou de terceiros, incluindo conhecimentos e habilidades relativas às tecnologias da informação e sua gestão, e habilidades interpessoais necessárias para desempenhar suas tarefas de maneira efetiva (Ray et al, 2005; Kim et al, 2011). Embora tais competências geralmente sejam de grande valor para uma empresa, há ampla disponibilidade no mercado e considerável possibilidade de imitação e de transferência para outras firmas. De modo condizente, os resultados reportados na literatura (Ray et al, 2005; Tian et al, 2010) indicam que tais conhecimentos e habilidades per se não explicam a variação no desempenho de um processo de negócio entre concorrentes. Estudos sugerem, contudo, que elas podem atuar em conjunto com outros recursos e capacidades de uma organização e, assim, contribuir para melhorar o desempenho de seus processos e os resultados do negócio (Huang, 2010; Tonolli et al, 2012). Em particular, competências técnicas em TI parecem ter um efeito positivo na capacidade de uma empresa de obter e aplicar novos conhecimentos (Moreno Jr. et al, 2012), e gerenciar e utilizar de maneira efetiva seus recursos tecnológicos (Kim et al, 2011).

Recursos tecnológicos são ativos de TI que podem ser desenvolvidos ou adquiridos no mercado por uma empresa (Przyczynski \& Vanti, 2012). No contexto dos processos de back office, por exemplo, eles incluem tecnologias voltadas para a digitalização e gerenciamento eletrônico de documentos, sistemas integrados de gestão ou sistemas ERP, redes de computadores e de telecomunicações etc. (Ray et al, 2005). A grande oferta desses ativos no mercado e seu potencial para imitação, no entanto, limita sua capacidade de gerar vantagem competitiva sustentável (Hitt \& Brynjolfsson, 1996; Wade \& Hulland, 2004). Autores como Duncan (1995), Powell and Dent-Micallef (1997), Armstrong and Sambamurthy (1999), Jeffers et al. (2008) e Nevo and Wade (2010) observam que investimentos em tais recursos, por si só, não explicam adequadamente a variação no desempenho dos processos de negócio entre firmas concorrentes (cf. Weill, Subramani \& Broadbent, 2002). Por outro lado, resultados empíricos reportados recentemente indicam que a flexibilidade da infraestrutura composta por recursos tecnológicos pode ser determinante para o desempenho de uma organização (Bhatt, Emdad, Roberts \& Grover, 2010; Kim et al, 2011; Moreno Jr. et al, 2012).

\section{Flexibilidade da infraestrutura de TI}

Em geral, a infraestrutura de TI de uma organização é constituída pelos ativos tecnológicos que servem de base para a construção de soluções mais específicas com as quais os usuários finais têm contato (Duncan, 1995), tais como hardware, redes de comunicação, sistemas operacionais e aplicativos básicos para processamento de dados (Byrd \& Turner, 2000; Jeffers et al, 2008). Vários estudos apontam a flexibilidade da infraestrutura de TI como um antecedente do desempenho organizacional (Weill et al, 2002; Sambamurthy, Bharadwaj \& Grover, 2003; Kim et al, 2011).

A capacidade de uma firma de construir uma infraestrutura de TI flexível, com níveis altos de escalabilidade e adaptabilidade, influencia seu custo operacional, sua agilidade e o valor gerado pela adoção de inovações tecnológicas (Broadbent \& Weill, 1997; Tallon \& Pinsonneault, 2011). Tais benefícios resultam da maior rapidez de adaptação do suporte prestado por TI às áreas de negócio, quando da identificação de oportunidades e ameaças que exijam mudanças na organização (Weill et al, 2002; Ray et al, 2005; Bush, Tiwana \& Rai, 2010; Moreno Jr. et al, 2012). Por exemplo, num estudo recente, Bhatt et al. (2010) verificaram que a flexibilidade da infraestrutura de TI de empresas de manufatura e serviços está positivamente associada à maior geração e disseminação de informação, que, por sua vez, influenciam a capacidade de uma organização responder a novas demandas e desafios, e a sua competitividade.

\section{MODELO PROPOSTO}

A fim de contribuir para a ampliação do conhecimento sobre o tema, o presente estudo elabora e testa uma revisão do modelo de Ray et al. (2005), que está representada graficamente na Figura 1. Nos próximos parágrafos, as hipóteses associadas ao modelo proposto são delineadas. Embora representem proposições aplicáveis a diferentes tipos de processos e ambientes de negócio, as hipóteses foram adaptadas ao contexto específico da pesquisa, ou seja, os processos de back office.

Diferentemente do que foi feito por Ray et al. (2005), o modelo proposto inclui explicitamente o alinhamento operacional como um antecedente do desempenho do processo de negócio, que, por sua vez, influencia o desempenho global da organização (Kearns \& Sabherwal, 2006; Moreno Jr. et al, 2012; Przyczynski \& Vanti, 2012; Tonolli et al, 2012). Conforme foi feito em outros estudos (Devaraj \& Kohli, 2000; Ray et al, 2005), adotou-se a satisfação percebida dos clientes (internos e externos) da área responsável pela execução do processo (no caso, uma área de back office) como proxy do desempenho organizacional. Isso porque é razoável esperar que, em média, o desempenho organizacional das empresas em que os clientes dos processos de back office se sintam bem atendidos seja 
superior ao de empresas onde isso não acontece. Propõem-se, portanto, as seguintes hipóteses:

Hipótese 1: O desempenho do processo da área de back office tem um efeito positivo e direto na satisfação dos clientes desse processo.

Hipótese 2: $O$ nível de alinhamento operacional entre a área de $\mathrm{TI}$ e a área de back office tem um efeito positivo $e$ direto no desempenho do processo de negócio executado pelo back office.

De modo geral, para que recursos de TI (tecnológicos e humanos) se traduzam em valor para o negócio, é indispensável que sejam alocados, gerenciados e utilizados de acordo com as reais necessidades da empresa (Moreno Jr. et al, 2009; Preston \& Karahanna, 2009; Reich \& Benbasat, 2000; Tallon, 2008). Mesmo quando esses recursos estão disponíveis em ní- veis apropriados, seu uso, muitas vezes, tem resultado num nível de serviço aquém das demandas de uma organização, fazendo com que seus processos de negócios apresentem desempenho subótimo (ex.: Gulla, 2011). Embora, por definição, sem que haja alguma disponibilidade de recursos e habilidades de TI, não possa haver alinhamento operacional, o grau de alinhamento operacional numa organização não parece ser determinado pela quantidade de recursos e habilidades técnicas de TI que ela detém. Propõe-se, assim:

Hipótese 3a: As habilidades técnicas de TI não têm efeito direto no alinhamento operacional entre a área de $\mathrm{Tl}$ e a área de back office.

Hipótese 3b: Os recursos tecnológicos não têm efeito direto no alinhamento operacional entre a área de TI e a área de back office.

\section{Figura 1. Modelo proposto}

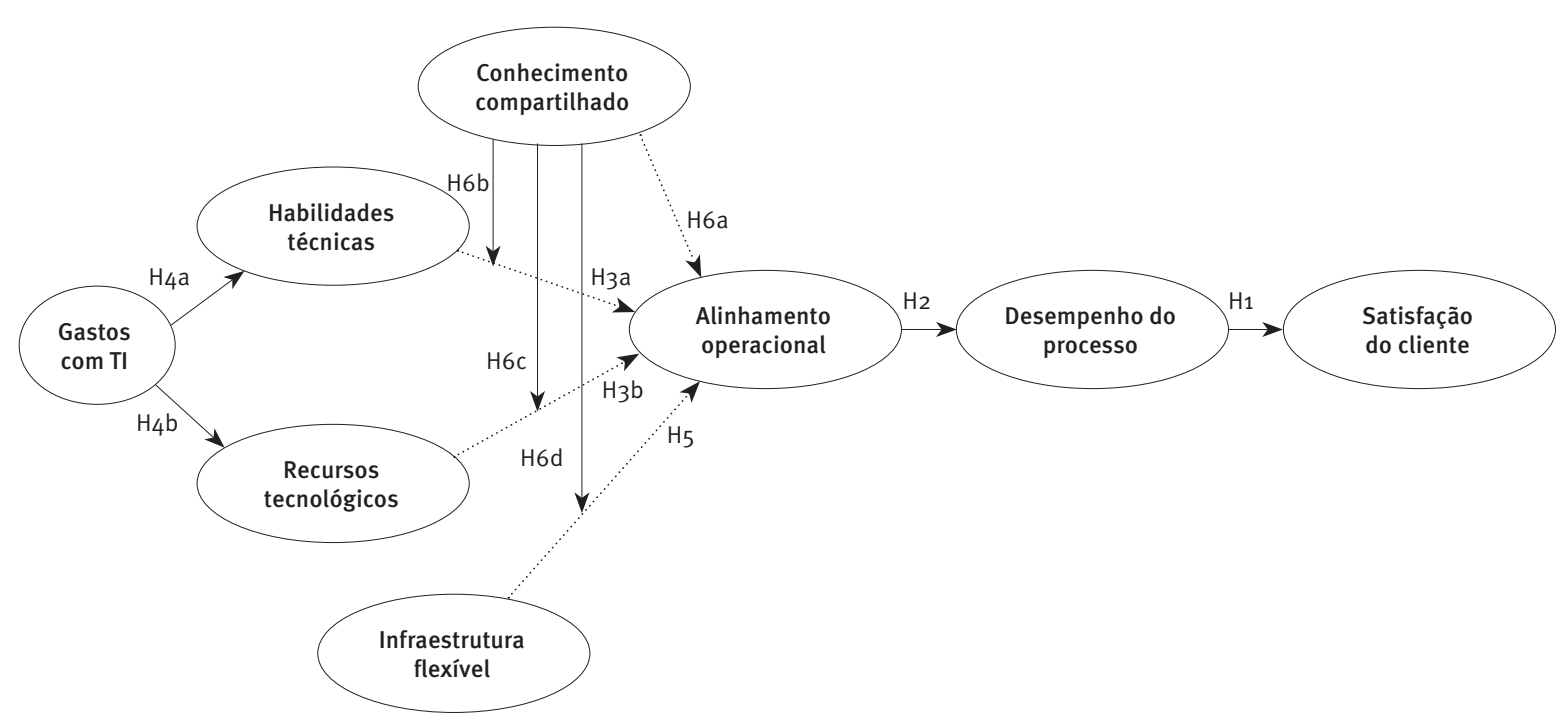

Ray et al. (2005) incluem em seu modelo um efeito direto dos gastos com TI no desempenho de processos de negócio. 0 nível de investimento em TI, contudo, não explica adequadamente a variação no desempenho de firmas concorrentes (Hitt \& Brynjolfsson, 1996; Jeffers et al, 2008; Nevo \& Wade, 2010). De fato, dada a complementaridade de recursos tecnológicos e organizacionais para a geração de vantagem competitiva (Wade \& Hulland, 2004; Nevo \& Wade, 2010), a falta de investimentos em recursos e capacidades associadas à TI, sejam internos ou providos por terceiros, pode deixar uma empresa em desvantagem para competir com seus concorrentes. Argumenta-se aqui, porém, que é a disponibilidade de recursos tecnológicos e humanos de TI para apoiar a exe- cução e gerenciamento dos processos de uma empresa que é determinada pelo montante por ela investido em TI, portanto qualquer efeito dos gastos com TI na geração de valor para o negócio deve ser totalmente mediado pelos construtos recursos tecnológicos e habilidades técnicas. Logo, propõe-se:

Hipótese 4a: Os gastos com TI de uma empresa terão um efeito positivo e direto em sua disponibilidade de habilidades técnicas de TI.

Hipótese 4b: Os gastos com TI de uma empresa terão um efeito positivo e direto em sua disponibilidade de recursos tecnológicos de TI. 
Tendo por base o conceito de dependência de trajetória (path dependence) definido na RBV, Ray et al. (2005) sustentam que, devido ao fato de tal processo estar sujeito às idiossincrasias do contexto histórico-social específico de cada organização, dificilmente seu resultado pode ser copiado ou transferido para concorrentes. Como consequência, infraestruturas flexíveis de TI tendem a ser capacidades valiosas e heterogeneamente distribuídas entre as firmas de um setor, contribuindo, assim, para explicar diferenças de competitividade (cf. Bush et al, 2010; Kim et. al, 2011; Tallon \& Pinsonneault, 2011; Moreno Jr. et al, 2012). Embora os processos de áreas de back office geralmente não envolvam o contato direto com o cliente, mudanças no ambiente externo de uma empresa podem exigir alterações substanciais na forma como ela opera e afetar, inclusive, esses processos. Uma estrutura de TI flexível reduziria, então, os custos e o tempo necessário para o desenvolvimento, adaptação e implantação dos sistemas que a apoiam.

Mesmo que uma infraestrutura de TI possa ser adaptada com facilidade e rapidamente, contudo, não há garantias de que as mudanças que venham a ser efetuadas atendam necessariamente os requisitos dos processos de negócios. De fato, as análises de Ray et al. (2005) não confirmaram essa associação. Tendo em vista que as causas mais frequentes de falhas em projetos de TI que visam aprimorar sistemas de informação são de natureza gerencial (Gulla, 2011), sugere-se que os benefícios de uma infraestrutura flexível são gerados apenas quando esse recurso é associado a outros recursos complementares da organização (Melville et al, 2004; Wade \& Hulland, 2004; Bush et al; 2010; Nevo \& Wade, 2010). Propõe-se, portanto:

Hipótese 5: A flexibilidade da infraestrutura de TI não tem um efeito positivo e direto no alinhamento operacional entre as áreas de TI e de back office.

Num estudo recente, Pee et al. (2010) verificaram que o compartilhamento de conhecimento media completamente a relação entre as interdependências sociais percebidas pelos profissionais de $\mathrm{Tl}$ e de negócios envolvidos em projetos de desenvolvimento de sistemas, e o desempenho desses projetos. Similarmente, pesquisas têm indicado que o grau de compartilhamento de conhecimento entre os gerentes de $\mathrm{Tl}$ e de negócios é capaz de explicar a variação no desempenho de processos entre empresas, já que permite um melhor projeto e implantação de soluções de TI que realmente atendam as necessidades dos processos que suportam (Lee et al, 1995; Nelson \& Cooprider, 1996; Fugate, Stank \& Mentzer, 2009; Pee et al, 2010; Ranganathan \& Sethi, 2002). Por outro lado, a aplicação efetiva dos conhecimentos compartilhados por profissio- nais de TI e de negócios só pode ocorrer quando há disponibilidade na organização de recursos e capacidades tecnológicos apropriados. Embora Ray et al. (2005) proponham em seu modelo que o compartilhamento de conhecimento influencia diretamente o desempenho de processos, os argumentos e resultados supracitados sugerem que é a aplicação adequada de recursos e capacidades de $\mathrm{TI}$, habilitada por esse compartilhamento, que tende a gerar um maior alinhamento operacional e, portanto, melhores resultados. Ressalta-se que autores como Wade and Hulland (2004), Melville et al. (2004) e Nevo and Wade (2010) defendem que recursos e capacidades de TI geram efeitos positivos no desempenho dos processos de negócios e no desempenho das empresas, se adequadamente integrados a recursos organizacionais complementares. Da mesma forma, como sugerido anteriormente, pode-se, também, argumentar que uma infraestrutura de TI flexível só será capaz de gerar valor para uma empresa quando seus gestores souberem como adaptá-la às necessidades emergentes dos processos da organização e tirar proveito das oportunidades que surgirem no seu ambiente de negócios. Logo, propõem-se as seguintes hipóteses:

Hipótese 6a: O nivel de compartilhamento de conhecimento entre profissionais das áreas de TI e de negócios não terá um efeito positivo direto no alinhamento operacional entre a área de $\mathrm{TI}$ e a área de back office.

Hipótese 6b: O nivel de compartilhamento de conhecimento entre as áreas de back office e de TI modera a relação entre as habilidades técnicas de TI e o alinhamento operacional: quanto maior o nivel de conhecimento compartilhado, mais intenso será o efeito da disponibilidade de habilidades técnicas de TI no alinhamento operacional entre as áreas de TI e de back office.

Hipótese 6c: O nivel de compartilhamento de conhecimento entre as áreas de back office e de TI modera a relação entre os recursos tecnológicos de TI e o alinhamento operacional: quanto maior o nivel de conhecimento compartilhado, mais intenso será o efeito da disponibilidade de recursos tecnológicos no alinhamento operacional entre as áreas de TI e de back office.

Hipótese 6d: O nivel de compartilhamento de conhecimento entre as áreas de back office e de TI modera a relação entre a flexibilidade da infraestrutura de TI e o alinhamento operacional: quanto maior o nivel de conhecimento compartilhado, mais intenso será o efeito da flexibilidade da infraestrutura de $\mathrm{TI}$ no alinhamento operacional entre as áreas de TI e de back office. 


\section{MÉTODO DE PESQUISA}

As hipóteses propostas no estudo foram testadas em uma amostra de empresas de serviços do estado do Rio de Janeiro. O foco em empresas de um único setor e de um mesmo estado deveu-se a duas questões básicas. Primeiro, o setor de serviços é tradicionalmente o que mais investe em TI (exs.: Beretti \& Cette, 2009; Santos, 2009). De acordo com os últimos dados do IBGE, o Rio de Janeiro respondia, em 2009, pelo segundo maior PIB brasileiro, com uma fatia de aproximadamente $11 \%$ do total, sendo que quase $73 \%$ do valor adicionado do Estado referia-se à prestação de serviços em áreas como telecomunicações, TI, seguros e comércio (Fundação Centro Estadual de Estatísticas, Pesquisas e Formação de Servidores Públicos do Rio de Janeiro, 2012). Por conseguinte, as chances de se obter uma amostra representativa e diversificada de empresas do setor de serviços tende a ser maior no Rio de Janeiro.

Em segundo lugar, as regiões do Brasil apresentam diferenças consideráveis nas suas características econômicas, sociais e culturais. A inclusão no estudo de variáveis de controle que representassem adequadamente tais variações exigiria modelos mais intricados e amostras maiores. Uma vez que o processo de coleta de dados envolvia uma complexidade razoável, por requerer a participação de pelo menos dois gestores por empresa e, ao mesmo tempo, proteger as suas identidades, optou-se por limitar o universo considerado no estudo. Dessa forma, foi possível, também, controlar a influência de variáveis contextuais regionais sobre os resultados.

Seguindo os procedimentos adotados em estudos empíricos sobre o alinhamento entre TI e negócio (exs.: Preston \& Karahanna, 2009; Ray et al, 2005), dados primários foram coletados com pares de gestores de áreas de back office e de TI das empresas. Como precondição para participação na pesquisa, todos os respondentes deveriam ser responsáveis, respectivamente, por um processo de back office considerado crítico em sua empresa e pelos recursos tecnológicos e humanos de Tl usados para apoiar aquele processo. Dessa forma, garantiu-se que os indivíduos mais amplamente informados sobre o objeto de estudo, e que, devido a suas funções, teriam uma visão abrangente do processo e de recursos e capacidades de Tl a ele associados, fornecessem os dados a serem analisados na pesquisa.

\section{Coleta de dados e amostra}

Dois questionários eletrônicos foram criados e disponibilizados no site SurveyMonkey.com, entre setembro e novembro de 2009: um com as escalas referentes aos construtos habili- dades técnicas, recursos tecnológicos, infraestrutura de TI flexível e conhecimento compartilhado, cujos itens deveriam ser avaliados pelos gestores de TI; e outro composto pelas escalas referentes aos construtos conhecimento compartilhado, alinhamento operacional, desempenho do processo de back office e satisfação do cliente, a ser avaliados pelos gestores das áreas de back office. Ambos levantaram dados demográficos do participante e características de sua empresa.

Como alguns dos construtos centrais ao estudo dizem respeito a processos de negócios, era importante que os respondentes tivessem uma visão transversal das atividades realizadas em suas empresas, assim como conhecimentos sobre a gestão dos processos em suas organizações. Além disso, uma vez que seriam coletados dados considerados sigilosos, tais como orçamentos, faturamento e satisfação de clientes, considerou-se importante promover a confiança dos participantes nos pesquisadores e, assim, aumentar a credibilidade das informações prestadas. Optou-se, portanto, por utilizar um processo de amostragem não probabilística por conveniência. Por intermédio de alunos e ex-alunos de programas de pós-graduação em Administração de uma instituição de ensino superior do Rio de Janeiro, foram feitos contatos com gestores da área de TI e de uma área de retaguarda considerada crítica para o negócio, em 90 empresas. Nas ligações, os pesquisadores confirmavam se os gestores atendiam às condições necessárias para participar no estudo, formalizavam o convite para participação na pesquisa e esclareciam dúvidas sobre procedimentos e objetivos. Para cada par de potenciais participantes, foi gerado um código único a ser utilizado no acesso ao questionário eletrônico, de modo a permitir sua posterior associação e garantir a confidencialidade das respostas. Ao final do período de coleta de dados, foram recebidos 39 pares de questionários completamente preenchidos, correspondendo a uma taxa de resposta de $43,3 \%$.

A amostra final contém gestores de empresas de diversos segmentos do setor de serviços, tais como Financeiro (21,12\%), Consultoria/Auditoria (21,12\%), Informática (16,90\%), Distribuição/Logística (7,04\%) e Telecomunicações (7,04\%). Aproximadamente $31 \%$ das empresas tinham no máximo 100 funcionários, e 33\%, pelo menos 500. De acordo com os critérios do Banco Nacional do Desenvolvimento [BNDES] (2012), 28\% delas seriam consideradas pequenas empresas, com um faturamento inferior a $\mathrm{R} \$ 16$ milhões, e $51 \%$, grandes empresas, com faturamento acima de $\mathrm{R} \$ 300$ milhões. No que tange a sua atuação, $65 \%$ das empresas atendiam o mercado nacional, $5 \%$, o estadual, e 30\%, o internacional, em seus respectivos segmentos. A Tabela 1 apresenta outras informações sobre as empresas que integram a amostra. 


\section{TABELA 1. Perfil das empresas participantes}

\begin{tabular}{|c|c|c|c|c|}
\hline Variável & Média & Desvio padrão & Mínimo & Máximo \\
\hline Receita (R\$ milhões) & $6.739,40$ & $29.661,80$ & 2,0 & $183.340,00$ \\
\hline Número de funcionários na área de TI & 56,70 & 132,60 & 2 & 550 \\
\hline
\end{tabular}

Uma grande variedade de processos de back office estavam contemplados na amostra, incluindo processos financeiros $(46,2 \%)$, de planejamento (12,8\%), comerciais (10,3\%), contábeis (7,7\%) e logísticos (7,7\%). Entre os gestores das áreas de back office, $23,1 \%$ reportaram exercer cargos de direção em suas empresas, e 76,9\%, cargos de gerência. Nas áreas de TI, 12,8\% dos gestores exerciam cargos de direção, e 87,2\%, cargos de gerência. Aproximadamente $84 \%$ dos gestores de TI e $64 \%$ dos de back office eram do sexo masculino. Mais de 70\% dos gestores de TI haviam concluído cursos de pós-graduação (MBA ou mestrado). Nas áreas de back office, esse percentual foi próximo de $61 \%$. A Tabela 2 mostra informações complementares sobre os respondentes.

\section{TABELA 2. Perfil dos respondentes}

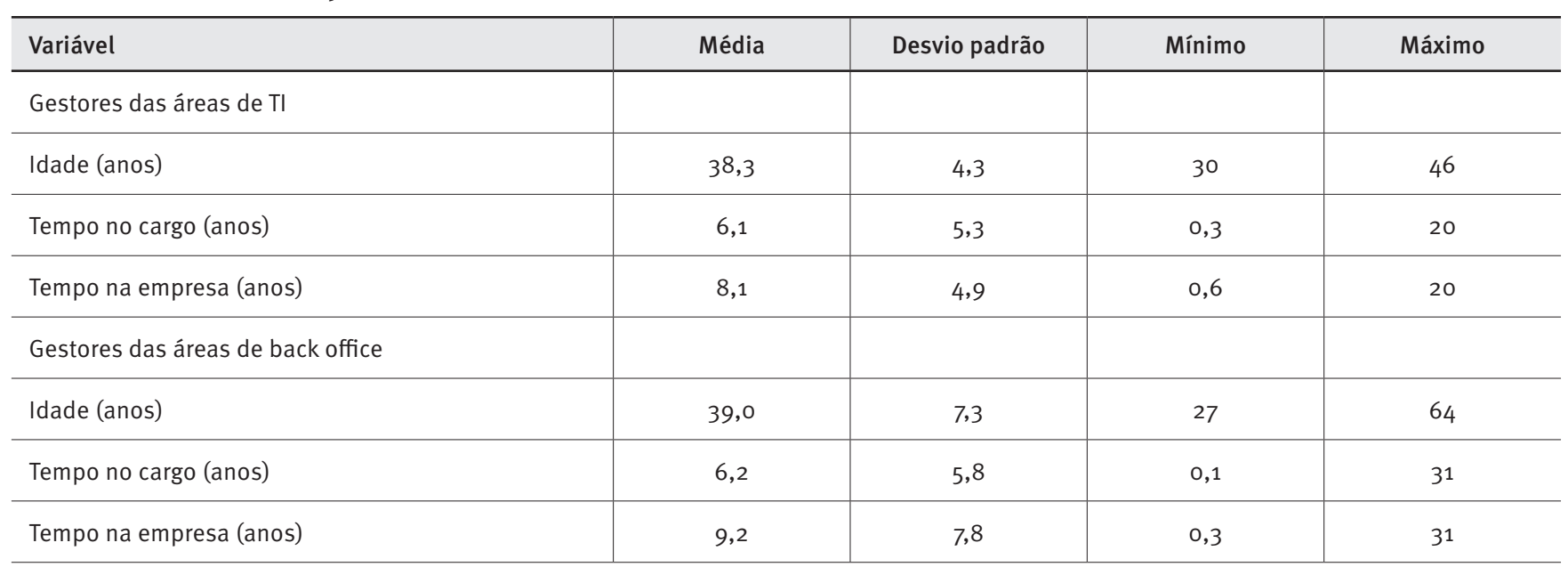

\section{Operacionalização dos construtos}

Ray et al. (2005) utilizaram uma escala desenvolvida por Leitheiser (1992) e Lee et al. (1995) para avaliar o construto habilidades técnicas de TI (HAB). Neste estudo, os três itens originais da escala foram ampliados e atualizados para contemplar competências usualmente demandadas no mercado de trabalho atual. Para garantir que o conjunto de competências representasse as habilidades de TI disponíveis no mercado, foram realizadas entrevistas com dois especialistas da área. Os tópicos definidos por eles foram posteriormente submetidos à avaliação de três gestores de TI de grandes empresas brasileiras, gerando uma escala composta por 11 itens. Considerou-se o construto formativo, uma vez que o domínio de cada uma dessas competências em uma equipe pode variar independentemen- te do domínio das demais competências (ex.s: Diamantopoulos, 2011; Kim, Shin \& Grover, 2010). As informações coletadas com a escala foram providas pelos gestores de TI das empresas participantes.

Da mesma forma, foi elaborada uma nova escala para medir os recursos tecnológicos de TI (REC), tendo por base o instrumento desenvolvido por Powell and Dent-Micallef (1997). Os tipos de tecnologia mencionados nas entrevistas pelos dois especialistas de TI e validados pelos gestores de TI supracitados foram organizados numa escala com 11 itens. Também nesse caso, o construto resultante foi considerado formativo. As informações foram fornecidas pelos gestores de TI das empresas participantes.

O construto gastos com TI (LogGASTI) foi avaliado por meio de uma pergunta aberta feita ao gestor da área de TI de 
cada empresa, solicitando o montante de investimentos e despesas com TI orçado para o ano corrente. Para evitar discrepâncias de magnitude entre as variáveis da pesquisa, utilizou-se o logaritmo na base 10 dos valores informados pelos respondentes.

Ray et al. (2005) utilizaram uma versão reduzida da escala desenvolvida por Duncan (1995) para mensurar o construto infraestrutura flexível de TI (FLEXTI). Seus itens, no entanto, refletem principalmente o grau de padronização da infraestrutura de TI e do compartilhamento de dados na empresa, e não a essência do construto em questão, isto é, a capacidade de ajustar facilmente a infraestrutura da empresa sempre que necessário. Por esse motivo, optou-se, no presente estudo, por criar uma nova escala, com itens que refletissem o grau de dificuldade, a rapidez e custos envolvidos em adaptações da infraestrutura de TI da organização. A métrica foi submetida à avaliação de cinco especialistas e gestores de TI, gerando uma escala com seis itens. Solicitou-se aos gestores de TI das empresas participantes que avaliassem sua infraestrutura de tecnologia usando essa escala.

A mensuração do construto conhecimento compartilhado (CON) foi feita por meio da escala criada por Ray et al. (2005) com base no instrumento de Boynton et al. (1994). A escala é composta por seis itens, sendo três avaliados pelos gestores das áreas de negócio da empresa e três pelos gestores de TI. As respostas refletem a opinião de um gestor de negócio sobre o quanto seu par em TI conhece aquela área, e vice-versa. 0 indicador da variável latente foi a média das respostas dadas por cada par de gestores.

Uma escala de oito itens foi desenvolvida para avaliar o construto alinhamento operacional entre TI e negócio (ALOP), com base em afirmativas que refletissem o domínio do construto conforme definido por Moreno Jr. et al. (2009). Os itens foram submetidos aos mesmos procedimentos de validação de face por especialistas utilizados nas demais escalas. A avaliação do alinhamento operacional foi feita por gestores de áreas de back office.

Também foi necessário elaborar uma escala para avaliar o construto desempenho do processo de back office (PERFBO). Novamente, seguiu-se um procedimento similar ao que foi acima descrito, gerando um conjunto de sete itens com validade de face aferida por cinco gerentes de áreas de negócios. Os gestores de áreas de back office das empresas fizeram essa avaliação.

Por fim, o construto satisfação do cliente do processo de back office (SATCLI) foi avaliado por meio de dois itens adaptados da escala utilizada por Ray et al. (2005). Os gestores das áreas de back office forneceram as informações.
Com exceção dos gastos com TI, todas os demais instrumentos anteriormente descritos foram respondidos por meio de escalas Likert de cinco pontos.

\section{ANÁLISE E RESULTADOS}

Os dados obtidos foram analisados de acordo com o método de modelagem de equações estruturais (Structural Equations Modeling - SEM) com base em PLS (Partial Least Squares) (cf. Urbach \& Ahlemann, 2010), no software SmartPLS v. 2.0 (Ringle, Wende \& Will, 2012). A opção pelo PLS deveu-se: (1) ao tamanho reduzido da amostra do estudo, (2) à facilidade de tratamento de moderações e de construtos formativos, e (3) à robustez do método a desvios da premissa de normalidade multivariada (Chin, 1998, 2010; Urbach \& Ahlemann, 2010). Para realizar os testes de significância dos parâmetros estimados, foi utilizado o método bootstrapping, com tamanho da amostra igual ao da amostra original, e mil reamostragens. Devido ao número pequeno de observações na amostra, os indicadores das variáveis latentes referentes aos construtos habilidades técnicas (HAB) e recursos tecnológicos (REC) foram substituídos pelas suas respectivas médias, conforme sugerido por Bollen (1989; cf. Stephenson \& Holbert, 2003).

\section{Modelo de mensuração}

O modelo de mensuração foi avaliado para verificar a validade convergente e discriminante e confiabilidade das escalas. Seguindo Chin (1998, 2010), avaliou-se primeiramente um modelo saturado, utilizando no cálculo das cargas a opção de ponderação fatorial (factor wheighting scheme), como subsequente comparação deste com o modelo teórico testado no estudo. Observaram-se, inicialmente, indicadores com cargas excessivamente baixas e não significantes $(a=0,05)$ para duas variáveis latentes correspondentes aos construtos flexibilidade da infraestrutura de TI (FLEXTI) e desempenho do processo (PERF). Dois itens foram removidos de cada escala, e a análise, refeita. Como pode ser visto na Tabela 3, os valores de confiabilidade composta (composite reliability) e alfa de Cronbach ( $\mathrm{aC}$ ) então obtidos para todas as variáveis foram acima de o,80 e 0,70, respectivamente, sendo considerados adequados (Bagozzi \& Yi, 1988; Hair, Black, Babin \& Anderson, 2009). Na Tabela 4, observa-se que todas as variáveis latentes compartilham com os seus itens uma proporção maior de variância do que com as outras variáveis, indicando sua validade discriminante. As escalas validadas são apresentadas no Quadro 1. 


\section{TABELA 3. Confiabilidade e validade convergente}

\begin{tabular}{|c|c|c|c|c|c|}
\hline Variáveis Latentes & Indicadores & Cargas & AVE & $\mathrm{CRb}$ & $\mathrm{aC}$ \\
\hline Alinhamento operacional (ALOP) & 8 & $0,59-0,84$ & 0,52 & 0,89 & 0,87 \\
\hline Desempenho do processo (PERF) & 5 & $0,60-0,84$ & 0,51 & 0,83 & 0,75 \\
\hline Gastos com TI (GASTI) & 1 & 1,00 & 1,00 & 1,00 & 1,00 \\
\hline Habilidades técnicas (HAB) & 1 & 1,00 & 1,00 & 1,00 & 1,00 \\
\hline Recursos tecnológicos (REC) & 1 & 1,00 & 1,00 & 1,00 & 1,00 \\
\hline FLEXTI * CON & 4 & $0,72-0,76$ & 0,56 & 0,84 & 0,74 \\
\hline $\mathrm{HAB} * \mathrm{CON}$ & 1 & 1,00 & 1,00 & 1,00 & 1,00 \\
\hline $\mathrm{REC} * \mathrm{CON}$ & 1 & 1,00 & 1,00 & 1,00 & 1,00 \\
\hline \multicolumn{6}{|c|}{ Todas as cargas estimadas foram estatisticamente significantes $(p<0,01)$. } \\
\hline \multicolumn{6}{|c|}{ Confiabilidade composta (composite reliability). } \\
\hline
\end{tabular}

\section{TABELA 4. Validade discriminante}

\begin{tabular}{|c|c|c|c|c|c|c|c|c|c|c|c|}
\hline $\begin{array}{l}\text { Variáveis } \\
\text { Latentes }\end{array}$ & ALOP & CON & PERF & FLEXTI & GASTI & HAB & REC & SAT & FLEXTI*CON & $\begin{array}{l}\text { HAB } \\
{ }^{\star} \mathrm{CON}\end{array}$ & $\begin{array}{c}\text { REC } \\
{ }^{\star} \mathrm{CON}\end{array}$ \\
\hline ALOP & $0,52^{\mathrm{a}}$ & & & & & & & & & & \\
\hline CON & 0,13 & 1,00 & & & & & & & & & \\
\hline PERF & 0,30 & 0,01 & 0,51 & & & & & & & & \\
\hline GASTI & 0,01 & 0,00 & 0,04 & 0,02 & 1,00 & & & & & & \\
\hline $\mathrm{HAB}$ & 0,02 & 0,01 & 0,00 & 0,03 & 0,14 & 1,00 & & & & & \\
\hline REC & 0,00 & 0,01 & 0,00 & 0,07 & 0,17 & 0,41 & 1,00 & & & & \\
\hline FLEXTI*CON & 0,29 & 0,06 & 0,10 & 0,02 & 0,00 & 0,01 & 0,00 & 0,06 & 0,56 & & \\
\hline $\mathrm{HAB}^{\star} \mathrm{CON}$ & 0,02 & 0,09 & 0,06 & 0,01 & 0,00 & 0,01 & 0,03 & 0,10 & 0,12 & 1,00 & \\
\hline $\mathrm{REC}^{*} \mathrm{CON}$ & 0,00 & 0,04 & 0,02 & 0,00 & 0,01 & 0,04 & 0,06 & 0,03 & 0,10 & 0,51 & 1,00 \\
\hline
\end{tabular}

a Os valores na diagonal correspondem aos AVEs das variáveis latentes. Os demais valores são correlações entre variáveis latentes. 
Quadro 1. escalas utilizadas para mensuração dos construtos

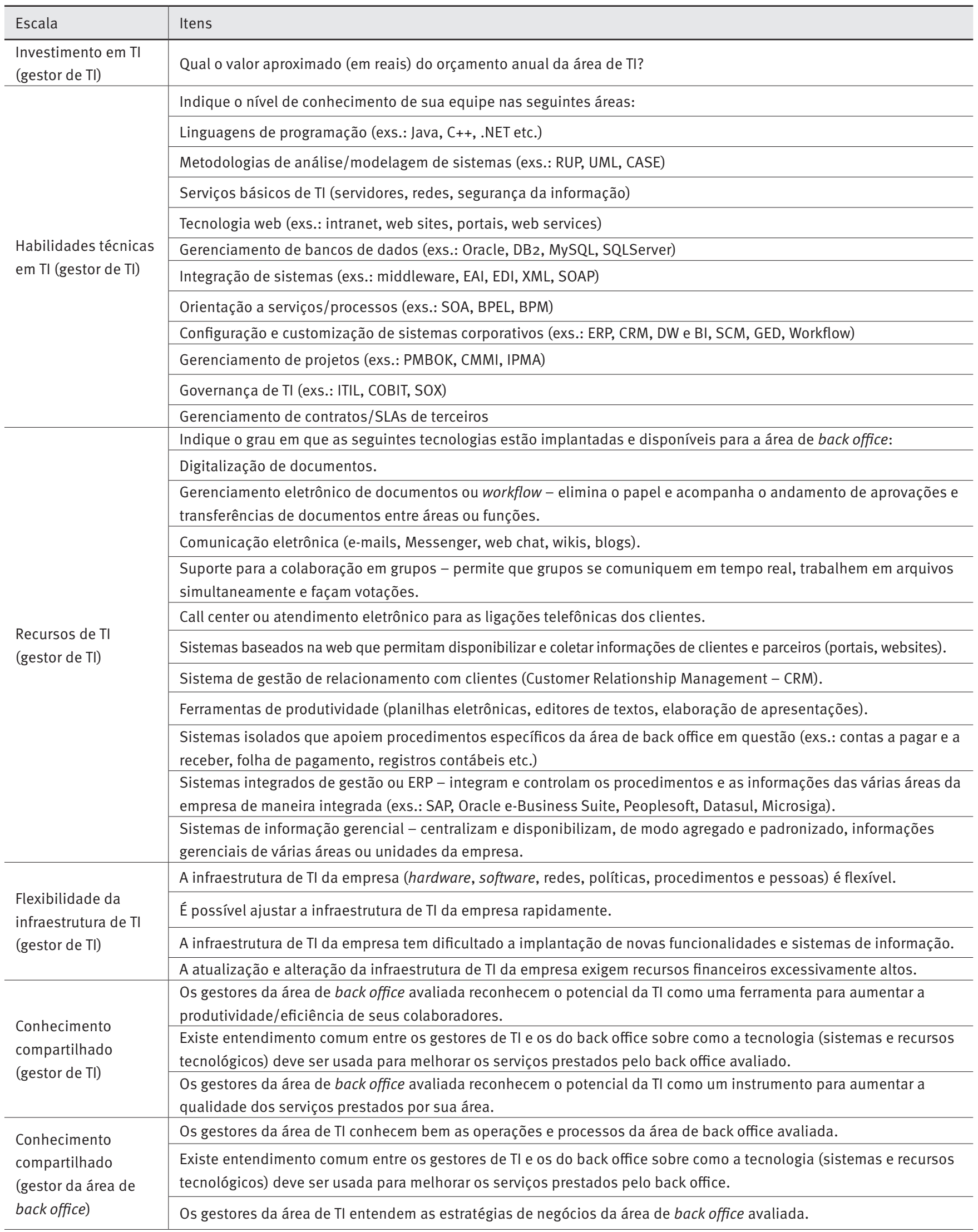


Quadro 1. escalas utilizadas para mensuração dos construtos (continuação)

\begin{tabular}{|c|c|}
\hline Escala & Itens \\
\hline \multirow{6}{*}{$\begin{array}{l}\text { Alinhamento } \\
\text { operacional (gestor } \\
\text { da área de back } \\
\text { office) }\end{array}$} & $\begin{array}{l}\text { Os sistemas de informação disponibilizados para a área de back office são plenamente aderentes aos processos de } \\
\text { negócio daquela área. }\end{array}$ \\
\hline & A área de TI sugere soluções tecnológicas adequadas às necessidades da área avaliada. \\
\hline & $\begin{array}{l}\text { Os colaboradores da área de back office têm ao seu dispor sistemas de informação com as funcionalidades } \\
\text { necessárias para desempenharem suas atividades adequadamente. }\end{array}$ \\
\hline & Os sistemas de informação estão sempre disponíveis ("no ar") quando a área de back office necessita utilizá-los. \\
\hline & A área de TI responde rapidamente às demandas da área de back office. \\
\hline & Os sistemas de informação utilizados pela área de back office incorporam as regras de negócio daquela área. \\
\hline \multirow{2}{*}{$\begin{array}{l}\text { Desempenho do } \\
\text { processo (gestor da } \\
\text { área de back office) }\end{array}$} & A área de back office presta um pronto atendimento aos clientes (externos e internos). \\
\hline & Os colaboradores do back office possuem autonomia para resolver os problemas dos clientes. \\
\hline \multirow{2}{*}{$\begin{array}{l}\text { Satisfação dos } \\
\text { clientes (gestor da } \\
\text { área de back office) }\end{array}$} & Como os clientes avaliam a qualidade dos serviços prestados pela área de back office? \\
\hline & Como você avalia a qualidade dos serviços prestados aos clientes pela área de back office nesse período? \\
\hline
\end{tabular}

\section{Modelo estrutural}

A Figura 2 mostra as estimativas geradas com o método PLS. 0 poder preditivo do modelo pode ser considerado adequado, com a variância explicada para a maioria das variáveis latentes acima de $30 \%$, sendo $43 \%$ para o alinhamento operacional. Os valores das estatísticas t para as cargas geradas com o método bootstrapping indicaram que apenas duas (H6b e H6c) das 11 hipóteses testadas não obtiveram suporte empírico. Conforme proposto, o desempenho do processo da área de back office parece ter um efeito positivo sobre a satisfação dos clientes daquela área $\left(\mathrm{H}_{1}\right)$. Esse desempenho tende a ser positivamente influenciado pelo nível de alinhamento operacional entre $\mathrm{TI}$ e a área de back office $\left(\mathrm{H}_{2}\right)$. Por outro lado, nenhum dos recursos e capacidades de TI (habilidades técnicas, recursos tecnológicos, infraestrutura flexível) nem o nível de compartilhamento de conhecimentos entre os profissionais das áreas de TI e de back office parecem contribuir, por si só, para a melhoria do alinhamento operacional ( $\mathrm{H}_{3} \mathrm{a}, \mathrm{H}_{3} b, \mathrm{H}_{5}$ e H6a). Além disso, parte da variação na disponibilidade de recursos tecnológicos e de habilidades técnicas nas empresas foi explicada pelos seus gastos com $\mathrm{TI}\left(\mathrm{H}_{4} \mathrm{a}\right.$ e $\left.\mathrm{H}_{4} \mathrm{~b}\right)$. Por fim, entre as interações previstas, apenas a que envolve o nível de conhecimento compartilhado e a flexibilidade da infraestrutura de TI foi estatisticamente significante $(p<0,05)$. Pode-se dizer, portanto, que, na medida em que as áreas de TI e de back office compartilham conhe- cimentos, intensifica-se o efeito positivo da flexibilidade da infraestrutura de $\mathrm{TI}$ da empresa no grau de alinhamento entre essas duas áreas (H6d).

Os dados e procedimentos descritos foram igualmente utilizados para estimar as cargas e coeficientes de determinação do modelo de Ray et al. (2005). Nenhuma das cargas estimadas foi estatisticamente significante $(a=0,05)$, de modo similar ao que foi observado pelos autores em sua pesquisa de campo. Além disso, o coeficiente $\mathrm{R} 2$ gerado para satisfação do cliente $\left(R_{2}=0,19\right)$ foi bastante inferior ao obtido com o modelo proposto neste estudo. Com base nos resultados de análises que empregaram técnicas estatísticas mais sofisticadas e robustas (PLS) do que as adotadas por Ray et al. (2005), pode-se, assim, concluir que o modelo aqui proposto apresenta um melhor ajuste aos dados coletados.

Apesar do uso de múltiplas fontes de informação na coleta de dados reduzir o potencial de viés de método comum (common method bias), algumas variáveis foram informadas pela mesma fonte. Foi, assim, empregado o teste de um fator de Harmon para avaliar esse viés (Podsakoff \& Organ, 1986; cf. Malhotra, Kim \& Patil, 2006; Patnayakuni, Rai \& Tiwana, 2007; Patnayakuni, Ruppel \& Rai, 2006). Uma vez que os dois fatores com o maior autovalor gerados para cada grupo de variáveis associadas a uma mesma fonte não responderam, respectivamente, por mais da metade da variância total da amostra, pode-se concluir que é improvável que os resultados das análises tenham sido afetados pelo viés de método comum. 
Figura 2. Resultados obtidos para o modelo proposto

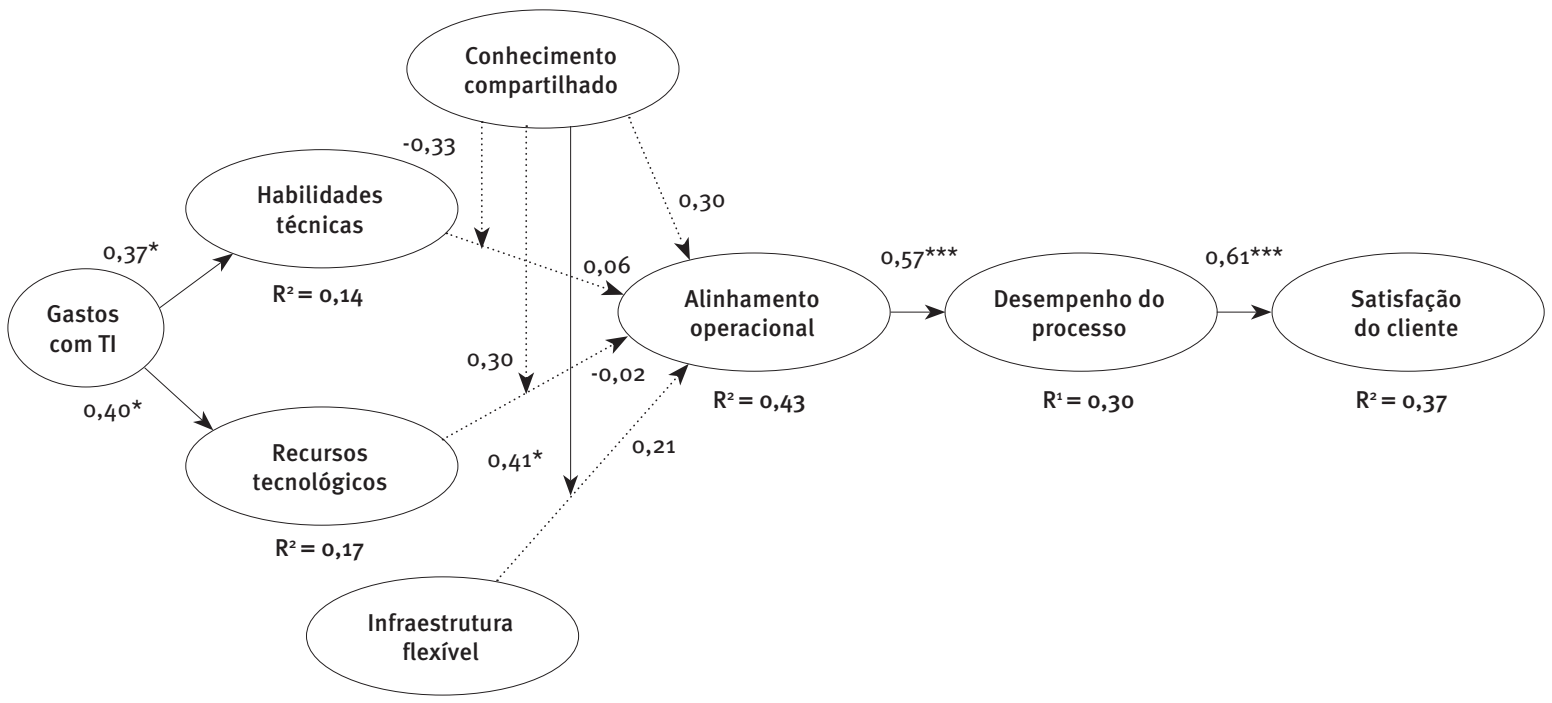

Nota: * p<0.05; ${ }^{* *}$ p<0,01; *** p<0,001; as demais cargas não foram estatisticamente significantes

Figura 3. Resultados obtidos para o modelo de Ray et al. (2005)

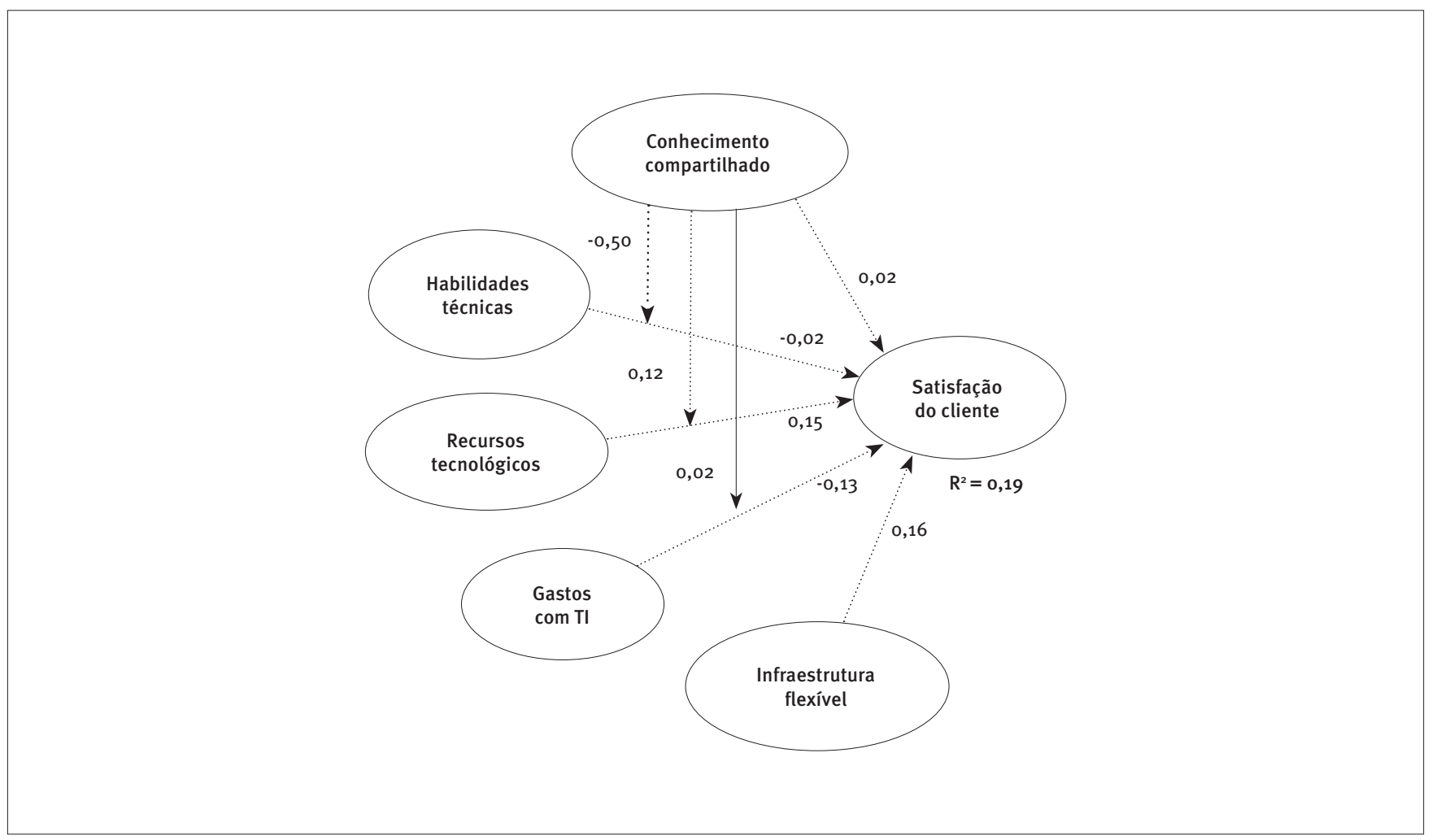

Nota: * p<0.05; ** p<0,01; *** p<0,001; as demais cargas não foram estatisticamente significantes 


\section{CONCLUSÃO}

O objetivo desta pesquisa foi avaliar os efeitos conjuntos de capacidades e recursos de $\mathrm{Tl}$ e do conhecimento compartilhado entre os gestores das áreas de TI e de negócios no alinhamento operacional entre essas áreas, e, consequentemente, no desempenho de processos executados pelas áreas de negócio. Uma revisão do modelo de Ray et al. (2005) foi proposta e testada estatisticamente com base em dados coletados nas áreas de $\mathrm{Tl}$ e de back office de empresas prestadoras de serviços do Rio de Janeiro. Os resultados das análises proveram suporte empírico para nove das 11 hipóteses propostas no estudo: apenas as moderações do conhecimento compartilhado nos efeitos de habilidades técnicas e recursos tecnológicos no alinhamento operacional não foram confirmadas.

Esta pesquisa oferece contribuições teóricas importantes para a investigação científica sobre a geração de valor para um negócio por meio de investimentos em TI. Primeiramente, o modelo proposto explicita a cadeia causal que interconecta investimentos em TI, recursos e capacidades de TI, o alinhamento operacional, o desempenho de um processo de negócio e a satisfação de seus clientes. Embora esse conjunto de relações tenha sido abordado, com pequenas variações, em estudos teóricos (exs.: MELVILLE et al, 2004; Wade \& Hulland, 2004; Nevo \& Wade, 2010), não foi possível encontrar, na literatura acadêmica, trabalhos que explicitassem de maneira completa e testassem os mecanismos por meio dos quais investimentos em TI potencialmente se traduzem em benefícios para o negócio.

Outra contribuição teórica desta pesquisa reside na revisão e complementação das hipóteses propostas por Ray et al. (2005) em um dos poucos estudos empíricos sobre o tema. Como observado no modelo proposto, a relação entre investimentos e recursos e capacidades de TI foi estabelecida, os efeitos diretos do conhecimento compartilhado e da flexibilidade da infraestrutura de TI foram revistos, e o efeito da interação entre essas duas últimas variáveis foi especificado. Além disso, integrou-se ao modelo o importante papel mediador do alinhamento operacional no desempenho dos processos de negócio. As hipóteses aqui delineadas, assim, constituem uma base mais consistente para futuras investigações sobre a geração de valor e vantagem competitiva por meio da TI. Em particular, este trabalho reforça a pertinência da RBV para explicar como a TI promove capacidades competitivas.

Por fim, nesta pesquisa, a utilização de técnicas de equações estruturais baseadas em PLS revelou efeitos estatisticamente significantes que não haviam sido detectados por Ray et al. (2005) em suas análises de regressão linear múltipla (RLM). Embora aqueles autores tivessem à sua disposição uma amos- tra consideravelmente maior do que a utilizada neste trabalho, o suporte empírico para suas hipóteses só foi obtido por meio de uma análise da variância (ANOVA), uma ferramenta de análise menos robusta. Limitações como a conversão forçada de variáveis mensuradas originalmente por métricas escalares em métricas categóricas, no caso da ANOVA, e a incerteza sobre a contribuição única dos diferentes preditores de um mesmo critério, devido à sequência de regressões independentes, são observadas naquele estudo e suplantadas neste trabalho. Os resultados obtidos no presente estudo, apesar de baseados em uma amostra de apenas 39 empresas, reforçam a validade das proposições teóricas retratadas no modelo testado, na medida em que foram avaliados por meio de um tratamento metodológico mais sofisticado.

No que tange às relações de causa e efeito aqui propostas, destaca-se a influência positiva do grau de alinhamento operacional entre Tl e as áreas de negócio no desempenho dos processos que essas últimas executam. Dessa forma, o presente estudo provê suporte empírico para as proposições, de autores tais como Asato et al. (2011), Moreno Jr. et al. (2009) e Tonolli et al. (2012), de que o alinhamento TI-negócio é um antecedente do desempenho dos processos organizacionais e que, por meio destes, pode alavancar os resultados globais do negócio.

Os resultados ratificam a noção de que recursos e capacidades de TI (habilidades técnicas, recursos tecnológicos, infraestrutura flexível), por si só, não são capazes de gerar um melhor alinhamento operacional entre as áreas de Tl e de negócios de uma empresa, corroborando os argumentos de diversos autores sobre o potencial limitado da mera disponibilidade desses recursos e capacidades para promover o alinhamento (Moreno Jr. et al, 2009; Nevo \& Wade, 2010; Preston \& Karahanna, 2009; Reich \& Benbasat, 2000; Tallon, 2008). Também foi observado que o nível de compartilhamento de conhecimentos entre os profissionais das áreas de TI e de back office parece não influenciar de maneira direta o alinhamento operacional entre essas áreas. Diferentemente do argumentado por outros autores (e.g., Tallon \& Pinsonneault, 2011; Ray et al. (2005), entretanto, verificou-se que, quando conhecimentos tendem a ser mais intensamente compartilhados entre as áreas, a relação entre o nivel de flexibilidade da infraestrutura de TI e o grau de alinhamento operacional entre suas áreas de Tl e de negócios intensifica-se. Esse efeito de interação entre o compartilhamento de conhecimento e a flexibilidade da infraestrutura de TI também é uma contribuição original deste estudo.

Nossa análise objetivou explicar as variações entre as organizações que participaram do estudo (cf. Ray et al. 2005) e que, apesar de seu número reduzido, representam um conjunto diversificado de empresas de serviços em termos de ta- 
manho e segmentos de negócios. Dado que a amostra utilizada não é probabilística, inferências sobre a validade do modelo para todo o universo de empresas de serviços exigem ressalvas. Novos estudos poderão ampliar a confiança na pertinência do modelo por meio de sua aplicação a amostras maiores e probabilísticas. Destaca-se, entretanto, que o tamanho de uma amostra tem influência direta sobre a potência dos testes estatísticos realizados, ou seja, a probabilidade de se detectar um efeito quando ele realmente ocorre na população (Hair et al, 2009). Em geral, quanto mais observações forem incluídas numa amostra, maior a potência do teste. Logo, o fato de a maioria das relações aqui propostas terem obtido suporte empírico, mesmo com uma amostra reduzida, sugere que a intensidade dos respectivos efeitos na população seja considerável, reforçando a validade do modelo proposto. Vale lembrar que a menor potência dos testes realizados pode ter sido a causa da rejeição de duas das 11 hipóteses testadas. Por outro lado, pode, também, ter gerado a confirmação das hipóteses que previam que os construtos habilidades técnicas, recursos tecnológicos e infraestrutura flexível não influenciariam o alinhamento operacional. Tais possibilidades devem ser examinadas em estudos futuros que empreguem amostras maiores e probabilísticas.

Apesar de os critérios utilizados para a seleção de empresas participantes aumentarem a validade interna do estudo, essas restrições também impedem a generalização dos achados para além do universo pesquisado. Nesse sentido, sugere-se que estudos futuros se baseiem em amostras de empresas de outras indústrias e regiões do País. Além disso, uma vez que se investigaram apenas processos de back office, recomenda-se que outros tipos de processos sejam contemplados em novas pesquisas. Da mesma forma, como a satisfação percebida do cliente é apenas um entre diversos indicadores de desempenho organizacional, estudos futuros devem incluir outros indicadores de desempenho global ou da competitividade das empresas nos setores em que atuam. Por fim, recomendase a realização de pesquisas longitudinais, quantitativas, qualitativas ou mistas, que possam capturar a dinâmica de desenvolvimento de recursos e capacidades de TI e organizacionais com potencial estratégico, assim como de seus efeitos relativos num negócio. Novos recursos e capacidades podem ser considerados, incluindo capacidades dinâmicas, que parecem ter especial importância para a competitividade de empresas que atuam em contextos de negócio voláteis e complexos (ex.: Teece, 2007).

Vale, ainda, ressaltar que as conclusões derivadas nesta pesquisa têm implicações práticas significativas. Em geral, organizações em todo o mundo realizam investimentos anuais consideráveis na aquisição e desenvolvimento de recursos de TI. Apesar disso, o retorno esperado, em termos da contribuição para o desempenho global do negócio, nem sempre se concretiza. Esta pesquisa evidenciou fatores que parecem ser críticos para a geração desses benefícios. Em particular, parece importante estimular a adoção de práticas gerenciais que viabilizem uma maior integração entre as áreas de TI e de negócios, de modo a promover a compatibilidade e sinergia entre os recursos e capacidades associados a $\mathrm{Tl}$ e os processos de negócios por eles suportados. 0 estudo ainda reforça a noção de que fatores organizacionais - aqui exemplificados pelo compartilhamento de conhecimentos - são preponderantes para a promoção de ajustes na infraestrutura tecnológica de uma organização, de modo a gerar um melhor desempenho de seus processos de negócios e da organização como um todo. A mera adoção da TI não é suficiente para garantir resultados: é a partir da integração entre recursos e capacidades tecnológicas e de negócio, viabilizados pela colaboração orquestrada entre os integrantes dessas áreas, que soluções mais efetivas podem vir a ser alcançadas.

\section{REFERÊNCIAS}

Armstrong, C, \& Sambamurthy, V. (1999). Information technology assimilation in firms: the influence of senior leadership and IT infrastructures. Information Systems Research, 10(4), 304-327.

Asato, R, Spinola, M. M, Costa, I, \& Silva, W. H. F. (2011). Alinhamento entre estratégia de negócios e melhoria de processos de software: um roteiro de implementação. Produção, 21(2), 314-328.

Bagozzi, R. P, \& Yi, Y. (1988). On the evaluation of structural equation models. Journal of the Academy of Marketing Science, 16(1), 74-94.

Banco Nacional do Desenvolvimento. (2012). Porte da empresa. Recuperado em 28 agosto, 2012, de http://www.bndes.gov.br/SiteBNDES/ bndes/bndes_pt/Navegacao_Suplementar/Perfil/porte.html.

Barney, J. (1991). Firm resources and sustained competitive advantage. Journal of Management, 17(1), 99-120.

Bassellier, G, \& Benbasat, I. (2004). Business competences of information technology professionals: conceptual development and influence on IT-business partnerships. MIS Quarterly, 28(4), 673-694.

Bassellier, G, Bensabat, I. E, \& Reich, B. H. (2003). The influence of business managers' IT competence on championing IT. Information Systems Research, 14(4), 317-336.

Beretti, P.-A, \& Cette, G. (2009). Indirect ICT investment. Applied Economics Letters, 16(17), 1713-1716.

Bhatt, G, Emdad, A, Roberts, N, \& Grover, V. (2010). Building and leveraging information in dynamic environments: the role of IT infrastructure flexibility as enabler of organizational responsiveness and competitive advantage. Information \& Management, 47(7-8), 341-349.

Bhatt, G. D, \& Grover, V. (2005). Types of information technology capabilities and their role in competitive advantage: an empirical study. Journal of Management Information Systems, 22 (2), 253-277. 
Bollen, K. A. (1989). Structural equations with latent variables. New York: Wiley.

Boynton, A. C, Zmud, R. W, \& Jacobs, G. (1994). The influence of IT management practice on IT use in large organizations. MIS Quarterly, 18(3), 299-318.

Broadbent, M, \& Weill, P. (1997). Management by maxim: how business and IT managers can create IT infrastructures. Sloan Management Review, 38(3), 77-92.

Bush, A. A, Tiwana, A, \& Rai, A. (2010). Complementarities between product design modularity and IT infrastructure flexibility in IT-enabled supply chains. IEEE Transactions on Engineering Management, 57(2), 240-254.

Byrd, T. A, \& Turner, D. E. (2000). Measuring the flexibility of information technology infrastructure: exploratory analysis of a construct. Journal of Management Information Systems, 17(1), 167-208.

Chin, W. W. (1998). The partial least squares approach to structural equation modeling. In Marcoulides, G. A. Modern methods for business research (pp. 1295-1336). Mahwah: Lawrence Erlbaum.

Chin, W. W. (2010). How to write up and report PLS analyses. In Vinzi, V. E. et al. (Eds.). Handbook of partial least squares: Springer handbooks of computational statistics (pp. 655-690). Berlin: Springer-Verlag.

Devaraj, S., \& Kohli, R. (2000). Information technology payoff in the healthcare industry: a longitudinal study. Journal of Management Information Systems, 16(4), 41-67.

Diamantopoulos, A. (2011). Incorporating formative measures into covariance-based structural equation models. MIS Quarterly, 35(2), 335-358.

Duncan, N. B. (1995). Capturing flexibility of information technology infrastructure: a study of resource characteristics and their measure. Journal of Management Information Systems, 12(2), 37-57.

Fundação Centro Estadual de Estatísticas, Pesquisas e Formação de Servidores Públicos do Rio de Janeiro (2012). Produto interno bruto do estado do Rio de Janeiro. Fundação Centro Estadual de Estatísticas, Pesquisas e Formação de Servidores Públicos do Rio de Janeiro (CEPERJ). Recuperado em 27 agosto, 2012, de http://www.fesp.rj.gov. $\mathrm{br} / \mathrm{ceep} / \mathrm{pib} / \mathrm{pib} . h \mathrm{tml}$.

Fugate, B, Stank, T, \& Mentzer, J. (2009). Linking improved knowledge management to operational and organizational performance. Journal of Operations Management, 27(3), 247-264.

Gulla, J. (2011, agosto 7-12). Seven reasons why information technology projects fail. SHARE Conference, Orlando, EUA. Recuperado em 6 julho, 2012, de https://share. confex. com/share/117/webprogram/Handout/ Session9341/seven\%20Reasons\%20Why\%2olnformation\%20Technology\%20Projects\%2oFail. pdf.

Hair, J. F, Black, W, Babin, B, \& Anderson, R. E. (2009). Multivariate data analysis. Upper Saddle River: Prentice Hall.

Henderson, J. C, \& Venkatraman, N. (2004). Cinco princípios para tirar o máximo da TI. In Davenport, T. H, Marchand, D, \& A. Dickson, T. Dominando a gestão da informação. Porto Alegre: Bookman.

Hitt, L. M, \& Brynjolfsson, E. (1996). Productivity, business profitability, and consumer surplus: three different measures of information technology value. MIS Quarterly, 20(2), 121-142.

Huang, L. K. (2010). A resource-based analysis of IT personnel capabilities and strategic alignment. Journal of Research \& Practice in Information Technology, 42(4), 263-287.

Jeffers, P. I, Muhanna, W. A, \& Nault, B. R. (2008). Information technology and process performance: an empirical investigation of the interaction between IT and non-IT resources. Decision Sciences, 39(4), 703-735.
Kearns, G. S, \& Sabherwal, R. (2006). Strategic alignment between business and information technology: a knowledge-based view of behaviors, outcome, and consequences. Journal of Management Information Systems, 23(3), 129-162.

Kim, G, Shin, B, \& Grover, V. (2010). Investigating two contradictory views of formative measurement in information systems research. MIS Quarterly, 34(2), 345-365.

Kim, G, Shin, B, Kim, K. K, \& Lee, H. G. (2011). IT capabilities, process-oriented dynamic capabilities, and firm financial performance. Journal of the Association for Information Systems, 12 (7), 487-517.

King, M. J. (2003). Back office and beyond: a guide to procedures, settlements and risk in financial markets. Hampshire: Harriman House.

Kretzer, J, \& Menezes, E. A. (2006). A importância da visão baseada em recursos na explicação da vantagem competitiva. Revista de Economia Mackenzie, 4(4), 63-87.

Lee, D. M. S, Trauth, E. M. E, \& Farwell, D. (1995). Critical skills and knowledge requirements of IS professionals: a joint academic/industry investigation. MIS Quarterly, 19(3), 313-340.

Leitheiser, R. L. (1992). MIS skills for the 1990s: a survey of MIS managers' perceptions. Journal of Management Information Systems, 9(1), 69-91.

Malhotra, N. K, Kim, S. S, \& Patil, A. (2006). Common method variance in IS research: a comparison of alternative approaches and a reanalysis of past research. Management Science, 52 (12), 1865-1883.

Melville, N, Kraemer, K, \& Gurbaxani, V. (2004). Information technology and organizational performance: an integrative model of IT business value. MIS Quarterly, 28(2), 283-322.

Moreno Jr., V. A, Cavazotte, F, \& Valente, D. (2009). Strategic alignment and its antecedents: a critical analysis of constructs and relations in the international and Brazilian literatures. Journal of Global Information Technology Management, 12(2), 33-60.

Moreno Jr., V. A, Pinheiro, J. R. M, \& Joia, L. A. (2012). Resource-based view, knowledge-based view and the performance of software development companies: a study of Brazilian SMEs. Journal of Global Information Management, 20(4), 27-53.

Nelson, K. M, \& Cooprider, J. G. (1996). The contribution of shared knowledge to IS group performance. MIS Quarterly, 20(4), 409-432.

Nevo, S, \& Wade, M. R. (2010). The formation and value of IT-enabled resources: antecedents and consequences of synergistic relationships. MIS Quarterly, 34(1), 163-183.

Patnayakuni, R, Rai, A, \& Tiwana, A. (2007). Systems development process improvement: a knowledge integration perspective. IEEE Transactions on Engineering Management, 54(2), 286-300.

Patnayakuni, R, Ruppel, C. P, \& Rai, A. (2006). Managing the complementarity of knowledge integration and process formalization for systems development performance. Journal of the Association for Information Systems, 7(8), 545-567.

Pee, L. G, Kankanhalli, A, \& Kim, H.-W. (2010). Knowledge sharing in information systems development: a social interdependence perspective. Journal of the Association for Information Systems, 11(10), 550-575.

Podsakoff, P. M, \& Organ, D. W. (1986). Self-reports in organizational research: problems and prospects. Journal of Management, 12(4), 531-544.

Powell, T. C, \& Dent-Micallef, A. (1997). Information technology as competitive advantage: the role of human, business and technology resource. Strategic Management Journal, 18(5), 375-405. 
Preston, D. S, \& Karahanna, E. (2009). Antecedents of IS strategic alignment: a nomological network. Information Systems Research, 20(2), 159-179.

Przyczynski, R, \& Vanti, A. A. (2012). Recursos de tecnologia da informação sustentadores de vantagem competitiva: um estudo no setor metal-mecânico agroindustrial. RAM-Revista de Administração Mackenzie, 13(4), 171-205

Ranganathan, C, \& Sethi, V. (2002). Rationality in strategic information technology decisions: the impact of shared domain knowledge and IT unit structure. Decision Science, 33(1), 59-86.

Ray, G, Barney, J. B, \& Muhanna, W. A. (2004). Capabilities, business processes, and competitive advantage: choosing the dependent variable in empirical tests of the resource-based view. Strategic Management Journal, 25(1), 23-37.

Ray, G, Muhanna, W. A, \& Barney, J. B. (2005). Information technology and the performance of the customer service process: a resource-based analysis. MIS Quarterly, 29(4), 625-652.

Reich, B. H, \& Benbasat, I. (2000). Factors that influence the social dimension of alignment between business and information technology objectives. MIS Quarterly, 24(1), 81-113.

Ringle, C, Wende, S, \& Will, A. (2012). SmartPLS 2. o M3. Recuperado em 20 março, 2012, de http://www. smartpls. de.

Sambamurthy, V, Bharadwaj, A, \& Grover, V. (2003). Shaping agility through digital options: reconceptualizing the role of information technology in contemporary firms. MIS Quarterly, 27(2), 237-263.

Santos, C. (2009). Gasto em TI pelas empresas dobrou em 12 anos. PMKB - Project Management Knowledge Base. Recuperado em 28 agosto, 2012, de http://www.pmkb.com.br/artigos-mainmenu-25/825-gasto-em-ti-pelas-empresas-dobrou-em-12-anos.html.

Stephenson, M. T, \& Holbert, R. L. (2003). A Monte Carlo simulation of observable versus latent variable structural equation modeling techniques. Communication Research, 30(3), 332-354.
Tallon, P. P. (2008). A process-oriented perspective on the alignment of information technology and business strategy. Journal of Management Information Systems, 24(3), 227-268.

Tallon, P. P, \& Pinsonneault, A. (2011). Competing perspectives on the link between strategic information technology alignment and organizational agility: insights from a mediation model. MIS Quarterly, 35(2), 463-486.

Teece, D. J. (2007). Explicating dynamic capabilities: the nature and microfoundations of (sustainable) enterprise performance. Strategic Management Journal, 28(13), 1319-1350.

Tian, J, Wang, K, Chen, Y, \& Johansson, B. (2010). From IT deployment capabilities to competitive advantage: an exploratory study in China. Information Systems Frontiers, 12(3), 239-255.

Tonolli, E. J, Jr, Brodbeck, Â. F, \& Costa, C. A. (2012). Análise das relações dos elementos de alinhamento estratégico entre negócio e tecnologia da informação com o processo de desenvolvimento de produto. Revista de Administração Mackenzie, 13(2), 135-170.

Urbach, N, \& Ahlemann, F. (2010). Structural equation modeling in information systems research using partial least squares. Journal of Information Technology Theory and Application, 11(2), 5-40.

Wade, M. W, \& Hulland, J. (2004). The resource-based view and information systems research: review, extension, and suggestions for future research. MIS Quarterly, 28(1), 107-142.

Weill, P, Subramani, M, \& Broadbent, M. (2002). Building IT infrastructure for strategic agility. MIT Sloan Management Review, 44(1), 57-65.

Wernerfelt, B. A. (1984). A resource-based view of the firm. Strategic Management Journal, 5(2), 171-180.

Wong, T. C, Ngan, S.-C, Chan, F. T. S, \& Chong, A. Y.-L. (2012). A two-stage analysis of the influences of employee alignment on effecting business-IT alignment. Decision Support Systems, 53(3), 490-498. 